\title{
Increased lymphocyte sister chromatid exchange frequency in workers with exposure to low level of ethylene dichloride
}

\author{
Tsun-Jen Cheng ${ }^{\mathrm{a}, \mathrm{b}, *}$, Pei-Yi Chou ${ }^{\mathrm{a}}$, Mei-Lan Huang a ${ }^{\text {, Chung-Li Du }}{ }^{\mathrm{c}}$, \\ Ruey-Hong Wong ${ }^{\mathrm{a}}$, Pau-Chung Chen ${ }^{\mathrm{a}, \mathrm{b}}$ \\ ${ }^{a}$ Institute of Occupational Medicine and Industrial Hygiene, National Taiwan University College of Public Health, Taipei, Taiwan \\ ${ }^{\mathrm{b}}$ Center for the Research of Environmental and Occupational Diseases, College of Public Health, National Taiwan University, Taipei, Taiwan \\ ${ }^{\mathrm{c}}$ Institute of Occupational Safety and Health, Council of Labor Affairs, Executive Yuan, Republic of China
}

Received 19 November 1999; received in revised form 24 March 2000; accepted 27 March 2000

\begin{abstract}
The genotoxicity of low-level exposure to ethylene dichloride (EDC) and vinyl chloride monomer (VCM) in humans is not clear. We used lymphocyte sister chromatid exchange (SCE) frequency as a parameter to investigate the genotoxicity of low level EDC and VCM in VCM-manufacturing workers. The SCE frequency was determined for 51 male workers with exposure to VCM and/or EDC and for 20 male workers devoid of such exposure. Epidemiological data were obtained by questionnaire, and included history of smoking, drinking, and any medication taken, as well as a detailed occupational history. Personal- and area-sampling and analysis were conducted in order to calculate the time-weighted average (TWA) contaminant-exposure level corresponding to different job categories. Moderate EDC exposure around $1 \mathrm{ppm}$ corresponded to a significantly greater SCE frequency than was the case for the low EDC exposure group $(p<0.01)$. However, VCM exposure of similar level was not associated with increased SCE. We conclude that EDC may cause genotoxicity at a relatively low level of exposure. (C) 2000 Elsevier Science B.V. All rights reserved.
\end{abstract}

Keywords: Sister chromatid exchange; Smoking; Vinyl chloride; Ethylene dichloride

\section{Introduction}

Ethylene dichloride (EDC; CAS No. 107-06-2) has been used extensively industrially, greater than $90 \%$ of this use having been specifically designated for the

Abbreviations: VCM, vinyl chloride monomer; EDC, ethylene dichloride; SCE, sister chromatid exchange; TWA, time-weighted average.

*Corresponding author. Institute of Occupational Medicine and Industrial Hygiene, National Taiwan University College of Public Health, No. 1 Ren-Ai Road, Sec. 1, Taipei, 10018, Taiwan. Tel.: +886-2-23957845; fax: +886-2-23957845.

E-mail address: tcheng@ha.mc.ntu.edu.tw (T.-J. Cheng). manufacture of vinyl chloride monomer (VCM; CAS No. 75-01-4) [1]. While the carcinogenicity of EDC remains somewhat unclear, epidemiological and animal studies suggest that EDC might be associated with a variety of cancers [2,3]. Currently, EDC is classified by the International Agency for Research on Cancer (IARC) as a group 2B carcinogen, a possible human carcinogen [4], and gene mutation resulting from EDC exposure has been demonstrated in bacterial and animal models $[5,6]$. In an earlier mammalian assay, however, a micronucleus (MN) frequency change was not associated with EDC exposure [7] whereas sister chromatid exchange (SCE) frequency in mouse 
bone-marrow cells increased with EDC exposure subsequent to VCM exposure [8]. In addition, DNA binding with EDC was observed in mouse liver, kidney and lung [9,10]. Evidence of EDC-induced genotoxicity for humans, however, has been limited [1]. Thus, we conducted a study to investigate the genotoxicity of EDC for workers in a VCM-manufacturing plant.

$\mathrm{VCM}$ is produced through the cracking of EDC. In VCM-manufacturing plants, workers may be exposed, occupationally, to both VCM and EDC. Extensive study has been conducted to investigate the genotoxicity of VCM for workers in vinyl chloride polymerization plants [11]. Increased genotoxicity for VCM-exposed workers including SCE, chromosomal aberration and $\mathrm{MN}$ frequencies, has been demonstrated by a number of researchers $[12,13]$. The availability of genotoxicity data for low level VCM-exposure for humans appears limited, hence we also investigated the genotoxicity of occupational low-level VCM exposure in VCM-manufacturing industry.

A change from the normal frequency of SCE is one of the most sensitive markers of DNA damage and has been used previously to investigate the genotoxicity of a variety of different chemicals [14]. Previous studies have shown that workers exposed to VCM revealed a greater SCE frequency than controls [11-13]. SCE is also reported to be more sensitive than chromosomal aberration and $\mathrm{MN}$ formation for detecting genetic damage caused by VCM [13]. Thus, we used the SCE frequency as an index to determine if exposure to low levels of EDC and/or VCM would cause increased genotoxicity for VCM-manufacturing workers.

\section{Materials and methods}

\subsection{Study population and exposure assessment}

A total of 71 male workers were enrolled from two VCM-manufacturing plants. Personal and area air sampling was conducted in order to obtain EDCand VCM-exposure information according to a US National Institute of Occupational Safety and Health (NIOSH)-recommended method [15]. Estimated median EDC and VCM time-weighted average (TWA) contaminant exposure levels were assigned to each category of work as has been previously reported [16].
Among these study subjects, 20 employees working in the office or away from the manufacturing sites were presumed to have experienced neither EDC nor VCM exposure. EDC- or VCM-exposed workers were divided into low and moderate exposure groups with a contaminant-in-air level of $0.5 \mathrm{ppm}$ set as a cut-off point between the two categories. Twenty-three workers including mechanics, safety and hygiene officers and operators in control rooms experienced a low VCM-low EDC exposure (medians of VCM: $0.25-0.39$ ppm; medians of EDC: 0.2-0.29 ppm), while 20 workers including oxychlorination operators, EDC-unloading operators and field leaders were exposed to low VCM-moderate EDC exposure (medians of VCM: $0.16-0.27$ ppm; medians of EDC: 0.69-1.31 ppm). Eight workers, including VCM- and EDC-unloading operators and one employee with solely VCM-unloading exposure, were classified into a moderate VCM-moderate EDC exposure group (median of VCM: $1.63 \mathrm{ppm}$; median of EDC: $0.77 \mathrm{ppm}$ ).

\subsection{SCE assay}

The SCE frequency assay was performed according to a modified cytogenetic method [17]. Venous blood was collected in heparinized tubes from all subjects. One milliliter of whole blood was mixed with $9 \mathrm{ml}$ of PB-Max Karyotyping medium (Gibco BRL) containing RPMI 1640, L-glutamine, 10\% fetal bovine serum, penicillin (100 units/ml), streptomycin $(100 \mu \mathrm{g} / \mathrm{ml})$ and phytohemagglutinin. Cells were then incubated in $5 \% \mathrm{CO}_{2}$ in air at $37^{\circ} \mathrm{C}$ for $72 \mathrm{~h}$. After $24 \mathrm{~h}, 50 \mu \mathrm{M}$ of 5 -bromodeoxyuridine was added to the culture in order to achieve differential staining, and Colcemid (Gibco BRL) $(0.1 \mu \mathrm{g} / \mathrm{ml})$ was added $1.5 \mathrm{~h}$ before harvesting. The lymphocytes were then harvested in $75 \mathrm{mM}$ hypotonic $\mathrm{KCl}$ solution for $10 \mathrm{~min}$. Cells were subsequently washed twice and fixed in a methanol:acetic acid mix $(3: 1 ; \mathrm{v} / \mathrm{v})$. Slides were prepared by the air-dry technique. Chromosomes were stained by a modification of the fluorescence-plus Giemsa technique. Each slide was mounted with Sorensen's solution $(\mathrm{pH}=6.8)$, irradiated with the black light from two $15-\mathrm{W}$ lamps for 9 min and subsequently stained with a 5\% Giemsa stain for $5 \mathrm{~min}$. For each subject, 50 cells at metaphase were scored to determine the individual mean SCE frequency. All slides were scored by one reader blinded to the status of the subjects. 


\subsection{Epidemiological information}

We have collected specimen and epidemiological information from 71 workers employed at two VCM-manufacturing plants. Information pertaining to smoking and alcohol-consumption habits, medication consumption, and a detailed medical and occupational history was collected from study-participating employees via an interviewer-administered questionnaire. The smoking history included packs of cigarettes smoked daily, duration of smoking, and "pack-years" of cigarettes smoked. Pack-years were defined as packs smoked per day multiplied by years of smoking. Current smokers were defined as smokers who had been smoking for at least 6 months prior to blood collection. Alcohol-drinking was defined as alcoholic consumption on at least one occasion per week. Occupational history included job title, daily activity and a history pertaining to respirator use during current and/or past employment.

\subsection{Statistical analysis}

Comparisons were made between the different exposure groups for age, duration of employment and packs of cigarettes smoked each day using ANOVA, and for alcohol consumption and current smoking status using a $\chi^{2}$ test. Crude comparisons of SCE frequency among variables of interest including age and occupational exposure stratified by smoking status were subsequently conducted using ANOVA. Subsequent analysis used General Linear Models (GLM) with the dependent variable (SCE) as a function of age, smoking, alcohol consumption and exposure.

\section{Results}

Seventy-one male workers were included in this study. Demographic figures are summarized in Table 1. The mean age of subjects was 36.6 years. Current smokers accounted for $43.7 \%$ of study subjects.

The SCE frequency by age, cigarette-smoking status, duration of employment, alcohol consumption and exposure group is summarized in Table 2. The mean SCE frequency was 7.6 per cell. Current smokers exhibited a greater SCE frequency than those who were not current smokers (8.0 vs. $7.2 ; p<0.05$, $t$-test). Among the current smokers, the SCE frequency increased with exposure (controls, 6.8; low VCM-low EDC, 7.6; low VCM-moderate EDC, 8.8; moderate VCM-moderate EDC, 8.7). SCE frequency was significantly different among the control and exposure groups $(p<0.01)$. Among workers who were not current smokers, the SCE frequency also increased with exposure (controls, 6.7; low VCM-low EDC, 7.0; low VCM-moderate EDC, 8.2; moderate VCM-moderate EDC, 8.3). Again, SCE frequency was significantly different among control and exposure groups $(p<0.01)$.

Table 1

Characteristics of VCM manufacturing workers

\begin{tabular}{|c|c|c|c|c|c|}
\hline \multirow{2}{*}{$\begin{array}{l}\text { VCM exposure } \\
\text { EDC exposure }\end{array}$} & \multirow{2}{*}{$\begin{array}{l}\text { None } \\
\text { None }(N=20)\end{array}$} & \multicolumn{2}{|l|}{ Low } & \multirow{2}{*}{$\begin{array}{l}\text { Mod } \\
\operatorname{Mod}(N=8)\end{array}$} & \multirow[t]{2}{*}{ Total $(N=71)$} \\
\hline & & Low $(N=23)$ & $\operatorname{Mod}(N=20)$ & & \\
\hline Age (years) & $40.5 \pm 11.4^{\mathrm{a}}$ & $35.1 \pm 7.4$ & $34.8 \pm 8.3$ & $36.1 \pm 10.5$ & $36.6 \pm 9.4$ \\
\hline Duration of employment (years) & $9.7 \pm 7.9$ & $7.3 \pm 6.3$ & $7.1 \pm 5.4$ & $7.8 \pm 7.3$ & $8.0 \pm 6.6$ \\
\hline \multicolumn{6}{|l|}{ Drinking $^{\mathrm{b}}$} \\
\hline Yes & $10(50.0)^{\mathrm{c}}$ & $10(43.5)$ & $8(40.0)$ & $7(87.5)$ & $35(49.3)$ \\
\hline No & $10(50.0)$ & $13(56.5)$ & $12(60.0)$ & $1(12.5)$ & $36(50.7)$ \\
\hline \multicolumn{6}{|l|}{ Smoking $^{\mathrm{d}}$} \\
\hline Yes & $8(40.0)$ & $7(30.4)$ & $12(60.0)$ & $4(50.0)$ & $31(43.7)$ \\
\hline Pack/day & $0.7 \pm 0.3$ & $0.5 \pm 0.3$ & $0.7 \pm 0.4$ & $0.9 \pm 0.4$ & $0.7 \pm 0.4$ \\
\hline No & $12(60.0)$ & $16(69.6)$ & $8(40.0)$ & $4(50.0)$ & $40(56.3)$ \\
\hline
\end{tabular}

${ }^{\text {a Mean }} \pm$ SD.

${ }^{\mathrm{b}}$ Drinking, habitual alcohol drinking $\geq$ once a week.

${ }^{\mathrm{c}} N(\%)$.

${ }^{\mathrm{d}}$ Smoking, smoking during 6 months before blood collection. 
Table 2

SCE frequency by smoking status, EDC and VCM exposures and alcohol consumption in VCM manufacturing workers

\begin{tabular}{|c|c|c|c|c|}
\hline \multirow[t]{3}{*}{ Variables } & \multicolumn{3}{|c|}{ Smoking } & \multirow[t]{2}{*}{ Total } \\
\hline & \multicolumn{2}{|l|}{ No } & Yes & \\
\hline & $N$ & Mean \pm SD & $N$ Mean \pm SD & $N$ Mean \pm SD \\
\hline $\begin{array}{l}\text { Total } \\
\text { Age (years) }\end{array}$ & 40 & $7.2 \pm 1.1$ & $318.0 \pm 1.7 *$ & $717.6 \pm 1.4$ \\
\hline$<36$ & 20 & $7.4 \pm 1.2$ & $218.3 \pm 1.9$ & $417.9 \pm 1.6$ \\
\hline $\begin{array}{l}\geqslant 36 \\
\text { Duration of } \\
\text { employment } \\
\text { (years) }\end{array}$ & 20 & $7.1 \pm 1.1$ & $107.4 \pm 0.9$ & $307.2 \pm 1.0^{\dagger}$ \\
\hline$<5$ & 14 & $7.4 \pm 1.1$ & $98.0 \pm 1.5$ & $237.7 \pm 1.2$ \\
\hline $5-10$ & 14 & $7.1 \pm 1.2$ & $138.3 \pm 2.1$ & $277.7 \pm 1.8$ \\
\hline $\begin{array}{l}>10 \\
\text { Exposure }\end{array}$ & 12 & $7.2 \pm 1.2$ & $97.5 \pm 1.1$ & $217.3 \pm 1.1$ \\
\hline $\begin{array}{l}\text { None } \\
\text { Low VCM }\end{array}$ & 12 & $6.7 \pm 0.8^{\ddagger}$ & $86.8 \pm 1.8^{\ddagger}$ & $206.7 \pm 1.2^{\ddagger}$ \\
\hline Low EDC & 16 & $7.0 \pm 1.1$ & $77.6 \pm 1.5$ & $237.2 \pm 1.3$ \\
\hline Mod EDC & 8 & $8.2 \pm 1.0$ & $128.8 \pm 1.5$ & $208.5 \pm 1.3$ \\
\hline $\begin{array}{l}\text { Mod VCM } \\
\text { Mod EDC } \\
\text { Drinking }\end{array}$ & 4 & $8.3 \pm 0.9$ & $48.7 \pm 0.8$ & $88.5 \pm 0.8$ \\
\hline $\begin{array}{l}\text { Yes } \\
\text { No }\end{array}$ & $\begin{array}{l}14 \\
26\end{array}$ & $\begin{array}{l}7.7 \pm 1.3^{\dagger} \\
7.0 \pm 1.0\end{array}$ & $\begin{array}{ll}21 & 7.9 \pm 1.4 \\
10 & 8.2 \pm 2.2\end{array}$ & $\begin{array}{ll}35 & 7.8 \pm 1.3 \\
36 & 7.3 \pm 1.5\end{array}$ \\
\hline $\begin{array}{c}{ }^{*} p<0.05, \\
{ }^{\dagger} p<0.05, \\
\text { exposure grou } \\
{ }^{\dagger} p<0.01,\end{array}$ & con & n among & $\begin{array}{l}\text { mokers and nor } \\
\text { exposure grou }\end{array}$ & $\begin{array}{l}\text { n-smokers. } \\
\text { ups and non- } \\
\text { ups and non- }\end{array}$ \\
\hline
\end{tabular}

The multiple regression models were constructed to test the association of SCE frequency with potential variables using different comparison groups. In model 1, the low VCM-low EDC group had a higher SCE frequency than the control group, but this difference was not statistically significant. While, both the low VCM-moderate EDC and the moderate VCM-moderate EDC groups had a significantly higher SCE frequency than the control group. However, SCE frequency was not significantly different between the low VCM-moderate EDC and the moderate VCM-moderate EDC groups. In model 2, the low VCM-moderate EDC group had a significantly higher SCE frequency than the low VCM-low EDC group. Again, the moderate VCM-moderate EDC group did not have a higher SCE frequency than the low VCM-moderate EDC group. In both models, alcohol consumption was not associated with SCE
Table 3

Multiple regression model for SCE in VCM manufacturing workers

\begin{tabular}{|c|c|c|}
\hline & $\begin{array}{l}\text { Model } 1 \\
\text { Regression } \\
\text { coefficient } \\
\text { (95\% C.I.) }\end{array}$ & $\begin{array}{l}\text { Model } 2 \\
\text { Regression } \\
\text { coefficient } \\
\text { (95\% C.I.) }\end{array}$ \\
\hline Intercept & $\begin{array}{l}6.61 * * \\
(5.88,7.33)\end{array}$ & $\begin{array}{l}7.10 * * \\
(6.24,7.67)\end{array}$ \\
\hline Age $(\geqslant 36$ vs. $<36)$ & $\begin{array}{l}-0.18 \\
(0.80,0.44)\end{array}$ & $\begin{array}{l}-0.33 \\
(-1.03,0.37)\end{array}$ \\
\hline Smoking (pack/day) & $\begin{array}{l}0.89 * \\
(0.6,1.62)\end{array}$ & $\begin{array}{l}1.01 * \\
(0.20,1.83)\end{array}$ \\
\hline \multicolumn{3}{|l|}{ Exposure } \\
\hline Control & a & \\
\hline Low VCM Low EDC & $\begin{array}{l}0.46 \\
(-0.29,1.22)\end{array}$ & a \\
\hline Low VCM Mod EDC & $\begin{array}{l}1.57 * * \\
(0.79,2.34)\end{array}$ & $\begin{array}{l}1.06 * * \\
(0.32,1.80)\end{array}$ \\
\hline Mod VCM Mod EDC & $\begin{array}{l}1.56^{* *} \\
(0.56,2.55)\end{array}$ & $\begin{array}{l}1.06 * * \\
(0.09,2.03)\end{array}$ \\
\hline Model $R^{2}$ & 0.37 & 0.36 \\
\hline
\end{tabular}

\footnotetext{
${ }^{\text {a }}$ Reference group

${ }^{*} p<0.05$.

** $p<0.01$.
}

frequency. There was also no interaction between cigarette-smoking and chemical exposure upon SCE rate (Table 3).

\section{Discussion}

In this study, we found that smoking and exposure to EDC around $1 \mathrm{ppm}$ were associated with increased SCE frequency.

Previous reports have shown that smoking and age are associated with an increase in the SCE frequency $[18,19]$. We also found that cigarette-smoking was associated with increased SCE frequency in this study. However, we did not observe an association of age with SCE, probably because the range of age was small. The association of alcohol consumption with SCE frequency has been reported in alcoholics [20]. We did not observe the association of SCE frequency with alcohol consumption in this study. This may be due to the fact that our study subjects consumed relatively small amounts of alcohol. The association of alcohol consumption with SCE frequency was not observed in other studies $[18,19,21]$. 
In this study, the low VCM-low EDC, the low VCM-moderate EDC, and the moderate VCMmoderate EDC groups had significantly higher SCE than the control group. In order to further assess the effect of EDC or VCM alone on the SCE frequency, we used the low VCM-low EDC group as a baseline to compare to the low VCM-moderate EDC group, and the low VCM-moderate EDC group as a baseline to compare to the moderate VCM-moderate EDC group. We found that relatively low levels of EDC exposure may cause increased SCE frequency. However, we did not observe similar result for VCM exposure. SCE frequency increases with VCM exposure have been demonstrated in a number of previous reports [11]. Human studies suggest that VCM exposure at a contaminant-in-air level greater than 5 ppm could induce SCE frequency elevation [11], although, despite a comprehensive study design, we did not observe an elevated SCE frequency for workers with a VCM contaminant-in-air exposure level of around $1 \mathrm{ppm}$.

The SCE frequency increased with an EDC-in-air exposure level of around $1 \mathrm{ppm}$ in this current study. Currently, the maximum exposure level recommended by NIOSH (REL-TWA) and permissible by OSHA (PEL-TWA) is $1 \mathrm{ppm}$ in air for EDC. The threshold limit value (TLV-TWA) set by the American Conference of Governmental Industrial Hygienists (ACGIH) is $10 \mathrm{ppm}$, although this level is currently under revision.

To the best of our knowledge, this is the first human study indicating that EDC may elicit significant genetic damage at a relatively low level. It is advised that EDC exposure level should be maintained at below 1 ppm EDC in air, in order to prevent genetic damage.

VCM and EDC are similar in structure and may share common metabolic pathways [22]. Thus, potential synergism between VCM and EDC may affect genetic damage. However, we cannot demonstrate the synergism of VCM and EDC in the current study. Further investigation is needed to clarify this question. In conclusion, it is prudent to consider the genotoxic effects of EDC for VCM-manufacturing workers who are exposed to EDC.

\section{Acknowledgements}

This work was supported by a grant (IOSH86-M301) from the Institute of Occupational Safety and Health, and a grant (NSC86-2314-B-002-332) from the National Science Council, Taiwan, R.O.C.

\section{References}

[1] World Health Organization 1,2-Dichloroethane, Geneva: World Health Organization, Environ. Health Criter. 176 (1995).

[2] L.O. Benson, M.J. Teta, Mortality due to pancreatic and lymphopoietic cancers in chlorohydrin production workers, Br. J. Ind. Med. 50 (1993) 710-716.

[3] National Cancer Institute (NCI) Bioassay of 1,2-dichloroethane for possible carcinogenicity, Bethesda, MD, National Cancer Institute (HEW [NIH] Publication no. 78-1,305), 1978.

[4] International Agency for Research on Cancer (IARC) Monographs on the evaluation of carcinogenic risks to humans, Overall evaluations of Carcinogenicity: an updating of IARC monographs 1-42 (Suppl. 7) (1987) 373-376WHO (World Health Organization), IARC, Lyons.

[5] T.P. Simula, M.G. Glancey, C.R. Wolf, Human glutathione $S$-transferase-expressing salmonella typhimurium tester strains to study the activation/detoxification of mutagenic compounds: studies with halogenated compounds, aromatic amines and alfatoxin B1, Carcinogenesis 14 (1993) 13711376.

[6] H.A. Milman, D.L. Storyatorey, E.S. Riccio, A. Sivak, A.S. Tu, G.M. Williams, C. Tong, C.A. Tyson, Rat liver foci and in vitro assays to detect initiating and promoting effects of chlorinated ethenes and ethylenes, Ann. N. Y. Acad. Sci. 534 (1988) 521-530.

[7] D. Jessen, C. Ramel, The micronucleus test as part of a short-term mutagenicity test program for the prediction of carcinogenicity evaluated by 143 agents tests, Mutat. Res. 75 (1980) 191-202.

[8] A.K. Giri, S.S. Que Hee, In vivo sister chromatid exchange induced by 1,2-dichloroethane on bone marrow cells of mice, Environ. Mol. Mutagen. 12 (1988) 331-334.

[9] G. Prodi, G. Arfelini, A. Collacci, S. Grilli, M. Mazzulo, Interaction of halocompounds with nucleic acids, Toxicol. Pathol. 14 (1986) 438-444.

[10] G. Arfililni, S. Bartoli, A. Colacci, M. Mazzulo, M.C. Galli, G. Prodi, S. Grilli, In vivo and in vitro binding of 1,2-dibromoethane and 1,2-dichloroethane to macromolecules in rat and mouse organs, J. Cancer Res. Clin. Oncol. 108 (1984) 204-213.

[11] A.K. Giri, Genetic toxicity of vinyl chloride - a review, Mutat. Res. 339 (1995) 1-14.

[12] A.B. Sinues, M.L. Sanz, A. Tres, A. Alcala, J. Lanuza, C. Ceballos, M.A. Saenz, Sister chromatid exchanges, proliferating rate index, and micronuclei in biomonitoring of internal exposure to vinyl chloride monomer in plastic industry workers, Toxicol. Appl. Pharmacol. 108 (1991) 37-45.

[13] A. Fucic, D. Horvat, B. Dimitrovic, Mutagenicity of vinyl chloride in man: comparison of chromosome aberrations with micronucleus and sister chromatid exchange frequencies, Mutat. Res. 242 (1990) 265-270. 
[14] S. Wolff (Eds.), Sister Chromatid Exchange (1982) WileyNew York.

[15] National Institute for Occupational Safety and Health Manual of Analytical Method (1994) National Institute for Occupational Safety and HealthCincinnati.

[16] T.J. Cheng, M.L. Huang, N.C. You, C.L. Du, T.T. Chau, Abnormal liver function in workers exposed to low levels of ethylene dichloride and vinyl chloride monomer, J. Occup. Environ. Med. (1999) in press.

[17] R.H. Wong, J.D. Wang, L.L. Hsieh, C.L. Du, T.J. Cheng, Effects on sister chromatid exchange frequency of aldehyde dehydrogenase 2 genotype and smoking in vinyl chloride workers, Mutat. Res. 420 (1998) 99-107.

[18] F. Sarto, M.C. Faccioli, I. Cominatom, A.G. Levis, Aging and smoking increase the frequency of sister-chromatid exchange (SCE) in man, Mutat. Res. 144 (1985) 183-187.
[19] B. Husum, H.C. Wulf, E. Niebuhr, Sister chromatid exchange frequency correlates with age, sex and cigarette smoking in a 5 -year material of 553 healthy adults, Hereditas 105 (1986) $17-21$.

[20] M.G. Butler, W.G. Sanger, G.E. Veomett, Increased frequency of sister chromatid exchanges in alcoholics, Mutat. Res. 85 (1981) 71-76.

[21] R.S. Dewdney, D.P. Lovell, P.C. Jenkinson, D. Anderson, Variation in sister chromatid exchange among 106 members of the general U.K. population, Mutat. Res. 171 (1986) 4351.

[22] F.P. Guengerich, D.H. Kim, M. Iwasaki, Role of human cytochrome $P$-450 IIE1 in the oxidation of many low molecular weight cancer suspects, Chem. Res. Toxicol. 4 (1991) 168-179. 